\title{
Role of autolysin-mediated DNA release in biofilm formation of Staphylococcus epidermidis
}

\section{Correspondence \\ Soeren Molin \\ sm@biocentrum.dtu.dk}

Received 14 January 2007

Revised 7 February 2007

Accepted 9 February 2007

\author{
Zhigiang Oin, ${ }^{1} \dagger$ Yuanzhu Ou, ${ }^{1} \dagger$ Liang Yang, ${ }^{2}$ Yuli Zhu, ${ }^{1}$ \\ Tim Tolker-Nielsen, ${ }^{2}$ Soeren Molin ${ }^{2}$ and Di Ou ${ }^{1}$
}

\author{
${ }^{1}$ Key Laboratory of Medical Molecular Virology of Ministry of Education and Public Health, \\ Institutes of Biomedical Sciences and Medical Microbiology, Shanghai Medical School of Fudan \\ University Box 228, Yi Xue Yuan Road 138\#, Shanghai 200032, P. R. China \\ ${ }^{2}$ BioCentrum-DTU, Building 301, Technical University of Denmark, DK-2800 Lyngby, Denmark
}

\section{INTRODUCTION}

Bacteria in natural environments predominantly live in biofilms, i.e. surface-attached microbial communities embedded in a self-produced extracellular matrix (Costerton et al., 1995). The extracellular polymeric substance (EPS) matrix, which can constitute up to $90 \%$ of the biofilm biomass (Flemming et al., 2000), is a complex mixture of exopolysaccharides, proteins, DNA and other macromolecules (Sutherland, 2001). The EPS matrix plays a structurestabilizing role in biofilms, and it provides protection against some antibiotics and host-defence activities (Mah \& O’Toole, 2001; Stewart \& Costerton, 2001).

In recent years, coagulase-negative Staphylococcus epidermidis has become a serious nosocomial pathogen, frequently causing infections associated with implanted foreign materials (Rupp \& Archer, 1994). Biofilm formation is a major factor determining S. epidermidis pathogenicity in such device-associated infections (Rupp et al., 2001). S. epidermidis biofilm formation has been described as a two-step process (Gotz et al., 2000). The first stage involves attachment of cells to a surface (initial attachment

†These authors contributed equally to this work.

Abbreviations: CLSM, confocal laser scanning microscopy; DDAO, 7hydroxy-9H-(1,3-dichloro-9,9-dimethylacridin-2-one); EPS, extracellular polymeric substance; $\mathrm{Pl}$, propidium iodide. phase). The second stage includes cell-cell aggregation and the formation of a multilayered architecture (accumulative phase). Much attention has been focused on the polysaccharide intercellular adhesion (PIA) component of the EPS matrix of $S$. epidermidis, which is considered a major cell-to-cell interconnecting compound during biofilm formation (Heilmann et al., 1996a; Mack, 1999). However, it is possible that other matrix components may be important for biofilm development of $S$. epidermidis, such as extracellular DNA, which has been shown to be important for biofilm formation of Pseudomonas aeruginosa, Streptococcus intermedius and Streptococcus mutans (Whitchurch et al., 2002; Nemoto et al., 2003; Petersen et al., 2004, 2005; Allesen-Holm et al., 2006). In P. aeruginosa biofilms, extracellular DNA functions as a cell-cell interconnecting compound and structural component, and its production has been shown to be regulated via quorum sensing (Allesen-Holm et al., 2006).

In this study, we show that extracellular DNA is present in cultures and biofilms of $S$. epidermidis strains under different growth conditions. The extracellular DNA is found as a major component required for initial bacterial attachment to surfaces, as well as for the subsequent early phase of biofilm development by S. epidermidis. Moreover, evidence is presented that release of extracellular DNA from S. epidermidis is mainly caused by the activity of the autolysin AtlE. 
Table 1. Bacterial strains, plasmids and primers used in the present study

Abbreviations: erm, erythromycin; ts, temperature sensitive.

\begin{tabular}{|c|c|c|}
\hline Strains and plasmids & Description & Source or reference \\
\hline \multicolumn{3}{|l|}{ Strains } \\
\hline Se886 & Biofilm-positive clinical isolate & This study \\
\hline Se698 & Biofilm-positive clinical isolate & This study \\
\hline Se340 & Biofilm-positive clinical isolate & This study \\
\hline Se527 & Biofilm-positive clinical isolate & This study \\
\hline SeRP62A & Biofilm-positive laboratory strain & Christensen et al. (1982) \\
\hline Se1457 & Biofilm-positive laboratory strain & Mack et al. (1992) \\
\hline Se1457 $\Delta a t l E$ & atle : : erm derivative of Se1457 & This study \\
\hline Se1457 $\Delta a t l E(\mathrm{pRC} 21)$ & atlE complementary strain & This study \\
\hline Se1457 $\Delta a t l E(\mathrm{pRB} 473)$ & atlE mutant carrying the control vector & This study \\
\hline \multicolumn{3}{|l|}{ Plasmids } \\
\hline pBT2 & ts Escherichia coli/Staphylococcus shuttle vector & Bruckner (1997) \\
\hline pBTatle & ts vector for allelic gene replacement of atlE in S. epidermidis & This study \\
\hline pRC21 & Plasmid pRB473 carrying full fragment of atlE gene & Heilmann et al. (1997) \\
\hline Primers & Restriction & Sequence $\left(5^{\prime}-3^{\prime}\right)^{*}$ \\
\hline \multicolumn{3}{|c|}{ Primers used for allelic gene replacement } \\
\hline upatlER1 & KpnI & CGGGGTACCTACTTACCGACTTCACCAA \\
\hline upatlEL1 & $X b a \mathrm{I}$ & GCTCTAGA TAACAGAACAGGATGGATTG \\
\hline downatlER1 & HindIII & CCCAAGCTTAGAATTAACCTTTGGTGTATAT \\
\hline downatlEL1 & NheI & CTAGCTAGCATTACAAATTACCG TCTATGG \\
\hline \multicolumn{3}{|c|}{ Primers used for identification of extracellular DNA derivation } \\
\hline $\operatorname{trpSR} 1$ & & ATGGAAACTTTATTCTCAGGAATTCAGCC \\
\hline $\operatorname{trpSL1}$ & & TTATCTTTTTCGACCTAAGCCCATTGC \\
\hline srrAR1 & & ATGACTA ACGAAATTT \\
\hline srrAL1 & & CTATTTAGTCGGTTCA \\
\hline $\operatorname{sigBR} 1$ & & CTGTCTTGCAGCTTCTTGTAAT \\
\hline $\operatorname{sigBL1}$ & & ATGGCGAAAGAGTCGAA ATCAG \\
\hline isaAR1 & & AAAAAAACAGTTATCGCTTCTA \\
\hline isaAL1 & & CTTTATAAGCGGCATTGATTT \\
\hline$y y c F R 1$ & & ATGACTAACGAAATTT \\
\hline$y y c F L 1$ & & CTATTTAGTCGGTTCA \\
\hline
\end{tabular}

${ }^{\star}$ Underlined type shows the restriction site.

\section{METHODS}

Bacterial strains, plasmids and growth media. All the bacterial strains and plasmids used in this study are listed in Table 1, of which Se886, Se698, Se340 and Se527 are clinical strains isolated from different patients with implanted catheter infection in Zhongshan Hospital (Shanghai, China). Tryptic soy broth (TSB; Oxoid) medium containing $0.25 \%$ glucose was used for biofilm formation in the static chamber system. AB medium (Clark \& Maaløe, 1967) supplemented with $0.3 \mathrm{mM}$ glucose and $3 \%$ TSB was used for biofilm cultivation in the flow-chamber system. Biofilms and batch cultures were grown at $37^{\circ} \mathrm{C}$, unless otherwise indicated. DNase I (Sigma) was used at a concentration of $2 \mathrm{mg} \mathrm{ml}^{-1}$ in medium supplemented with $\mathrm{MgCl}_{2}$ $(5 \mathrm{mM})$. SYTO 9 and propidium iodide (PI) (Live_Dead reagents, Molecular Probes) were used at a concentration of $1 \mu \mathrm{M}$ for staining live or dead bacteria in biofilms. DDAO [7-hydroxy-9H-(1,3dichloro-9,9-dimethylacridin-2-one)] (Molecular Probes) was used at a concentration of $1 \mu \mathrm{M}$ to stain extracellular DNA in biofilms. Antibiotics were used at the following concentrations: erythromycin, $10 \mu \mathrm{g} \mathrm{ml}^{-1}$; chloramphenicol, $10 \mu \mathrm{g} \mathrm{ml}^{-1}$; ampicillin, $100 \mu \mathrm{g} \mathrm{ml}^{-1}$.
Bacterial initial attachment assays. Initial cell attachment was tested as described elsewhere (Heilmann et al., 1996b). Briefly, cell suspensions from mid-exponential phase were diluted to $\mathrm{OD}_{600}=0.1$ in PBS, and then incubated in wells ( $1 \mathrm{ml}$ per well) of cover-glass cellculture chambers (Nunc) for $30 \mathrm{~min}$ at $37^{\circ} \mathrm{C}$, after which attached cells were identified by microscopy.

Construction of the S. epidermidis 1457 SatIE mutant. The atlE gene in S. epidermidis 1457 was inactivated via homologous recombination using the temperature-sensitive shuttle vector $\mathrm{pBT} 2$, as described elsewhere (Bruckner, 1997; Vuong et al., 2000). An XbaI/ HindIII-digested erythromycin-resistance cassette ( $\mathrm{erm}$ ) from plasmid pEC1 was inserted into the pBT2 plasmid, upon which PCRamplified regions flanking the atlE gene were cloned into the plasmid to construct the plasmid pBT2 $\Delta a t l E$. Sequences of the primers are listed in Table 1. Proper cloning of the erm fragment and atlE flanking regions in plasmid pBT2 $\Delta a t l E$ was verified by direct sequencing. S. epidermidis 1457 was transformed by electroporation with plasmid pBT $\triangle a t l E$, and a procedure promoting allelic displacement of the atlE gene was performed as described elsewhere (Bruckner, 1997). 
Proper allelic displacement of the atlE gene was verified by direct sequencing.

\begin{abstract}
Measurement of extracellular DNA in microtitre plate cultures. Overnight cultures grown in TSB medium containing $0.25 \%$ glucose were diluted to $\mathrm{OD}_{600}=0.001$ in $\mathrm{AB}$ medium supplemented with $0.5 \%$ glucose, $0.05 \mathrm{mM}$ PI and $10 \%$ TSB. The diluted cultures were transferred to wells of polystyrene microtitre plates ( $150 \mu \mathrm{l}$ per well) and incubated for $24 \mathrm{~h}$ at $37^{\circ} \mathrm{C}$, upon which PI absorbance was measured at $480 \mathrm{~nm}$ and cell density was measured by $\mathrm{OD}_{600}$ using a Wallac microtitre plate reader.
\end{abstract}

Extraction of S. epidermidis genomic DNA and extracellular DNA, and PCR. Bacteria were grown to late-exponential phase $\left(\mathrm{OD}_{600}=2.0\right)$ in $5 \mathrm{ml}$ TSB medium at $37^{\circ} \mathrm{C}$, and were then harvested by centrifugation. Bacterial pellets were resuspended in $500 \mu \mathrm{l}$ buffer containing $25 \%$ sucrose, $10 \mathrm{mM}$ Tris/ $\mathrm{HCl}(\mathrm{pH} 7.5)$ and $0.2 \mathrm{mg}$ lysostaphin (Sigma-Aldrich). After incubation at $37^{\circ} \mathrm{C}$ for $30 \mathrm{~min}$, bacterial genomic DNA was extracted with phenol/chloroformisoamyl alcohol, precipitated by ethanol and resuspended in TE buffer (10 mM Tris, $0.1 \mathrm{mM}$ EDTA, $\mathrm{pH}$ 8.0). Culture samples from late-exponential phase were centrifuged and the supernatant was filtered $(0.2 \mu \mathrm{m}$ pore-size $)$, after which $500 \mu$ filtered supernatant was transferred to a new Eppendorf tube. The extracellular DNA was precipitated with ethanol and resuspended in TE buffer. Primers for amplification of $\operatorname{trpS}$ (SERP0575, 569 129-570 118), srrA (SERP1055, 1101 714-1102439), sigB (SERP1677, 1722 805-1 723 575), isaA (SERP2138, 2164 774-2 165 481) and $y y c F$ (SERP2534, 2591 0852591786 ) were designed based on the S. epidermidis strain RP62A gemomic sequence (GenBank accession no. CP000029) from the National Center for Biotechnology Information (NCBI) genome database (http://www.ncbi.nlm.nih.gov). All primer sequences are listed in Table 1. All PCR reactions were performed using Taq DNA polymerase (TaKaRa). The PCR reaction was performed on a T3 Thermocycler (Biometra): $45 \mathrm{~s}$ at $95^{\circ} \mathrm{C}, 45 \mathrm{~s}$ at $52^{\circ} \mathrm{C}$ and $1 \mathrm{~min}$ at $72{ }^{\circ} \mathrm{C}$ for 28 cycles.

\section{Cultivation of S. epidermidis biofilms}

In polystyrene microtitre plates. Biofilm cultivation in polystyrene microtitre plates was carried out essentially as described by Christensen et al. (1985). Briefly, overnight cultures of S. epidermidis strains grown in TSB $(0.25 \%$ glucose $)$ medium were diluted $1: 200$. The diluted cultures were transferred to wells of polystyrene microtitre plates $(200 \mu \mathrm{l}$ per well $)$ and incubated at $37^{\circ} \mathrm{C}$ for $24 \mathrm{~h}$. At different time points $(0,6$ and $12 \mathrm{~h})$, DNase I $\left(2 \mathrm{mg} \mathrm{ml}^{-1}\right.$, SigmaAldrich) was added to the wells. After incubation, the wells were washed gently three times with $200 \mu$ sterile PBS, air-dried and stained with $2 \%$ crystal violet for $5 \mathrm{~min}$. Then, the plate was rinsed under running tap water, air-dried, the crystal violet was redissolved in ethanol and the absorbance was determined at $590 \mathrm{~nm}$.

In the static chamber system. Biofilms were grown in cover-glass cell-culture chambers (Nunc) as described previously (Jager et al., 2005; Qin et al., 2007). Briefly, overnight cultures of S. epidermidis strains grown in TSB $(0.25 \%$ glucose $)$ medium were diluted to $\mathrm{OD}_{600}=0.001$, then inoculated into wells of a chamber $(1.5 \mathrm{ml}$ per well) and incubated at $37^{\circ} \mathrm{C}$. After that, the chamber was washed gently four times with $1 \mathrm{ml}$ sterile PBS, then stained by SYTO 9, PI or DDAO for $15 \mathrm{~min}$ and observed under the microscope.

In the flow-chamber system. Biofilms were grown in a flow chamber with individual channel dimensions of $1 \times 4 \times 40 \mathrm{~mm}$. The flowchamber system was assembled and prepared as described previously (Moller et al., 1998). The flow chambers were inoculated by injecting $350 \mu \mathrm{l}$ overnight culture diluted to $\mathrm{OD}_{600}=0.001$ into each flow channel with a small syringe. After inoculation, flow channels were left without flow for $1 \mathrm{~h}$, after which medium flow $\left(0.2 \mathrm{~mm} \mathrm{~s}^{-1}\right)$ was started using a Watson-Marlow 205S peristaltic pump.

Microscopy and image acquisition. All microscopic observations and image acquisition were performed with a Zeiss LSM 510 confocal laser scanning microscope (Carl Zeiss, Jena) equipped with detectors and filter sets for monitoring SYTO 9, PI and DDAO fluorescence. Images were obtained using a $\times 63 / 1.4$ objective or a $\times 40 / 1.3 \mathrm{i}$ objective. Simulated 3D images and sections were generated using the IMARIS software package (Bitplane).

Cell autolysis assays. Autolysis assays for S. epidermidis strains were performed as described by Brunskill \& Bayles (1996). Cell samples $(50 \mathrm{ml})$ were collected from exponential-phase cultures growing in TSB medium $\left(\mathrm{OD}_{580}=0.7\right)$ containing $1 \mathrm{M} \mathrm{NaCl}$, and cells were pelleted by centrifugation. The cells were washed twice with $50 \mathrm{ml}$ ice-cold water and resuspended in $50 \mathrm{ml} 0.05 \mathrm{M}$ Tris/HCl (pH 7.2) containing $0.05 \%(\mathrm{v} / \mathrm{v})$ Triton X-100. The cells were then incubated at $30{ }^{\circ} \mathrm{C}$ with shaking, and $\mathrm{OD}_{580}$ was measured at 30 min intervals.

\section{RESULTS}

\section{Effects of DNase I on biofilm formation of S. epidermidis}

The effect of DNase I on biofilm formation by S. epidermidis in the wells of polystyrene microtitre plates was investigated with six different strains. Strains 1457 and RP62A are reference strains, whereas strains Se886, Se698, Se340 and Se527 are clinical isolates from infected patients. When DNase I $\left(2 \mathrm{mg} \mathrm{ml}^{-1}\right)$ was added to the medium prior to inoculation of the microtitre plates, biofilm formation of all six S. epidermidis strains was severely reduced (Fig. 1a). When DNase I was added to established $6 \mathrm{~h}$ microtitre-plate-grown biofilms, the majority of the $S$. epidermidis biofilms were affected to some extent by the DNase I treatment, whereas the biofilm formed by strain Se886 appeared not to be affected by the DNase I treatment (Fig. 1a). Established $12 \mathrm{~h}$ microtitre-plate-grown biofilms of all the S. epidermidis strains appeared resistant to DNase I treatment (Fig. 1a). The presence of RNase (DNase-free, $\left.2 \mathrm{mg} \mathrm{ml}^{-1}\right)$ or heat-inactivated DNase I $\left(2 \mathrm{mg} \mathrm{ml}^{-1}\right)$ did not inhibit biofilm formation (Fig. 1a), indicating that inhibition of biofilm formation by DNase I was not due to a non-specific protein effect. A titration experiment showed that the lower limit for inhibition of biofilm formation by DNase I in the microtitre plate assay was $\sim 0.1 \mathrm{mg}$ DNase $\mathrm{I} \mathrm{ml}^{-1}$ (Fig. 1b). The addition of DNase I to growing cultures had no observable effect on the growth rate for any of the S. epidermidis strains (data not shown).

\section{Effects of DNase I on initial attachment of S. epidermidis}

S. epidermidis biofilm formation is a two-step process consisting of initial cell attachment and an accumulative phase (Mack, 1999; Gotz, 2002). We performed a microscopic examination of the effect of DNase I on attachment of $S$. epidermidis in a static chamber setup. After $30 \mathrm{~min}$ incubation under static conditions without DNase I, 
(a)

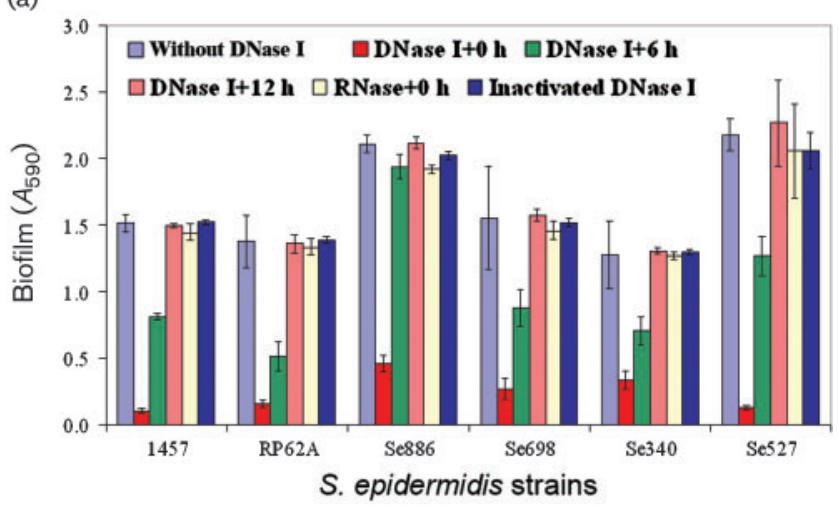

(b)

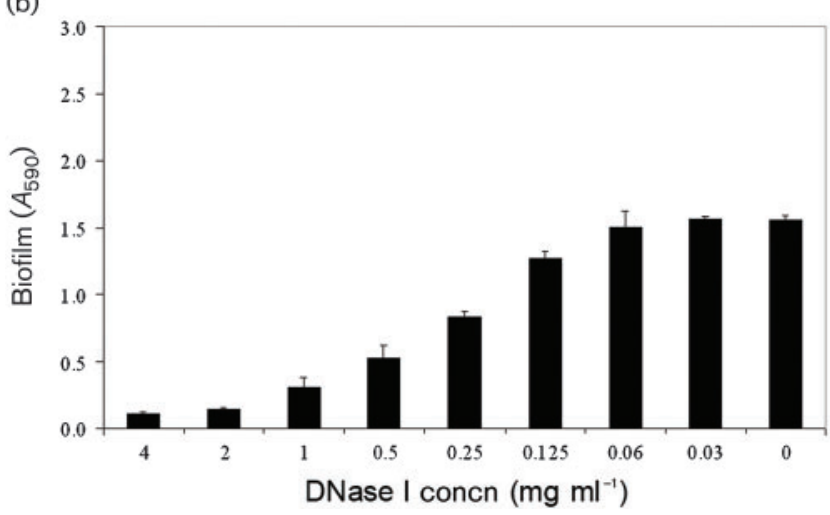

Fig. 1. (a) Effect of nuclease activity on biofilm formation in polystyrene microtitre plates of various $S$. epidermidis strains. Cultures were grown in TSB medium for $24 \mathrm{~h}$ at $37^{\circ} \mathrm{C}$ without DNase I, with DNase I ( $2 \mathrm{mg} \mathrm{ml}^{-1}$ ) added initially and after 6 and $12 \mathrm{~h}$, with RNase $\left(2 \mathrm{mg} \mathrm{ml}^{-1}\right)$ added initially, or with heatinactivated DNase I (2 mg ml${ }^{-1}$ ) as a control added initially. (b) Effects of various concentrations of DNase I on biofilm formation in polystyrene microtitre plates of $S$. epidermidis 1457. Cultures were grown in TSB medium for $24 \mathrm{~h}$ at $37{ }^{\circ} \mathrm{C}$ with DNase I added initially. The biofilm biomass was quantified using a crystal violet assay. The values are means of eight replicates, and the error bars indicate SD.

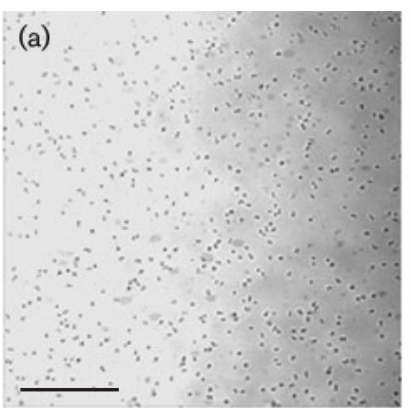

(b)

Fig. 2. Surface attachment of $S$. epidermidis 1457 in static chambers containing medium without DNase I (a) or with DNase I (b). Bars, $20 \mu \mathrm{m}$. numerous S. epidermidis 1457 cells had attached to the chamber surface (Fig. 2a). However, in chambers supplemented with DNase I, attachment of S. epidermidis 1457 to the surface was significantly reduced (Fig. 2b), indicating that extracellular DNA plays a role in the initial bacterial attachment. Heat-inactivated DNase I was found not to prevent S. epidermidis cell attachment (data not shown). Similar results were obtained for $S$. epidermidis strains RP62A, Se886, Se698, Se340 and Se527 (data not shown).

\section{Comparative PCR amplification from chromosomal and extracellular S. epidermidis DNA}

In order to investigate the nature of the S. epidermidis extracellular DNA, we purified extracellular DNA and chromosomal DNA from late-exponential-phase cultures of S. epidermidis, and performed comparative PCR. The genes $y y c F, \operatorname{trp} S, \operatorname{srr} A$, sigB and isaA, which are located in different regions of the $S$. epidermidis RP62A chromosome (GenBank accession no. CP000029; Gill et al., 2005), could all be amplified by PCR with both chromosomal and extracellular DNA as template (Fig. 3), indicating that the extracellular DNA is similar to chromosomal DNA.

\section{Role of AtIE in DNA release and biofilm formation of S. epidermidis}

Heilmann et al. (1997) have reported that atlE, encoding a major autolysin, is necessary for primary attachment and biofilm development of $S$. epidermidis in the wells of microtitre trays. It was shown that the AtlE protein is located at the cell surface of $S$. epidermidis, but the use of antibodies failed to provide conclusive evidence that the AtlE protein is directly involved in mediating primary attachment. It is therefore possible that AtlE plays an

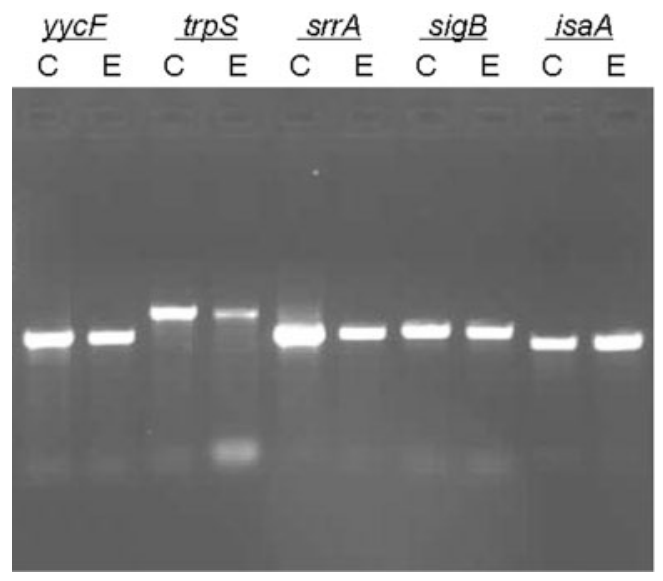

Fig. 3. PCR of purified $S$. epidermidis chromosomal DNA (C) or extracellular DNA (E) with primers targeting the $y y c F, \operatorname{trp} S$, srrA, $\operatorname{sig} B$ and isa $A$ genes. After $\mathrm{PCR}$, the amplification products were electrophoresed on an agarose gel. 
indirect role in S. epidermidis biofilm formation by promoting the release of extracellular DNA. In order to investigate the role of AtlE in DNA release and biofilm formation, we constructed an S. epidermidis 1457 atlE mutant $(\Delta a t l E)$. The mutation was confirmed by Southern blotting and direct sequencing (data not shown). The amounts of extracellular DNA in cultures of the $\triangle a t l E$ and parental strains were measured by PI staining in microtitre plates, as described previously by Allesen-Holm et al. (2006). Compared with the level in cultures of the 1457 wild-type strain, the amount of extracellular DNA in cultures of the $\triangle a t l E$ strain was dramatically decreased (Fig. 4a). In addition, the $\Delta a t l E$ strain was deficient in biofilm formation in the microtitre plates (Fig. 4a). A complemented strain, $\Delta a t l E(\mathrm{pRC} 21)$, was capable of releasing extracellular DNA and forming biofilm at levels

(a)

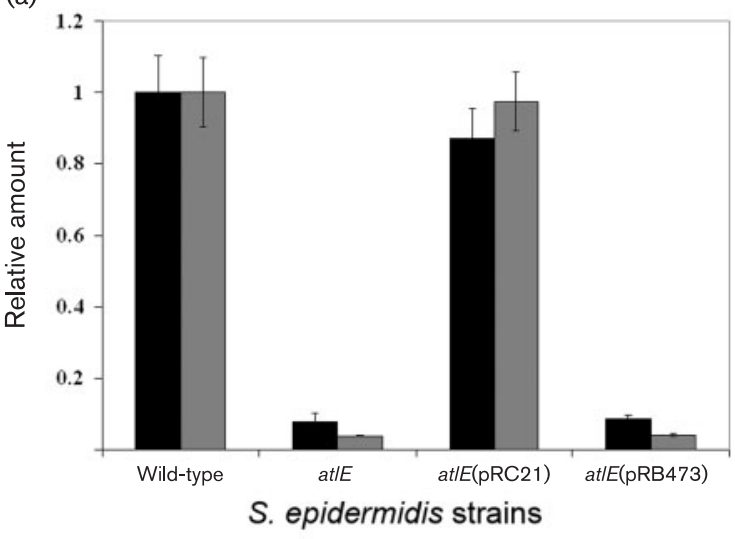

(b)

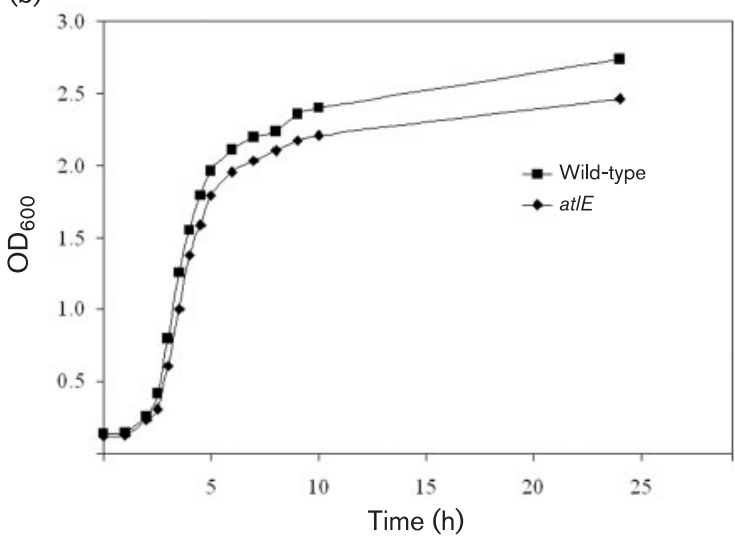

Fig. 4. (a) Relative amounts of extracellular DNA per $\mathrm{OD}_{600}$ unit (black bars), and relative amounts of biofilm (grey bars), in microtitre plate cultures of $S$. epidermidis 1457 wild-type, at/E, at $/ E(p R C 21)$ and at $/ E(p R B 473)$. The cultures were grown for $24 \mathrm{~h}$ in minimal medium supplemented with $0.05 \mathrm{mM} \mathrm{PI}$, whereupon $\mathrm{PI}$ absorbance $\left(A_{480}\right)$ and cell density $\left(O D_{600}\right)$ were measured. The biofilm biomass was quantified using a crystal violet assay. The values are means of eight replicates, and the error bars indicate SD. (b) Growth curves of the $S$. epidermidis 1457 wild-type and at/E mutant cultivated in TSB batch cultures. similar to that of the wild-type strain (Fig. 4a), whereas the vector control strain $\Delta a t l E(\mathrm{pRB} 473)$ released extracellular DNA and formed biofilm at levels similar to that of the $\triangle a t l E$ mutant (Fig. 4a). The $\Delta a t l E$ mutant grew at almost the same growth rate as its parental strain (Fig. 4b), indicating that the differences in extracellular DNA release and biofilm formation could not be attributed to differences in growth rate.

\section{Occurrence of extracellular DNA in S. epidermidis biofilms}

In a previous study we used DDAO to stain extracellular DNA in $P$. aeruginosa biofilms, because of its excellent fluorescent properties and high sensitivity (Allesen-Holm et al., 2006). Here, we used DDAO to stain extracellular DNA, and SYTO 9 to stain bacterial cells in S. epidermidis biofilms grown under static or hydrodynamic conditions. The spatial distribution of cells and extracellular DNA in the stained biofilms was visualized by confocal laser scanning microscopy (CLSM).

DDAO staining and subsequent CLSM indicated that extracellular DNA surrounded the wild-type adhering cells in the initial phase of biofilm development in the static chambers (Fig. 5a). However, extracellular DNA was not detected on the surface of the few adhering cells of the $\triangle a t l E$ strain (Fig. 5c). After $24 \mathrm{~h}$ in the static chamber, the 1457 wild-type had formed small microcolonies which contained large amounts of extracellular DNA (Fig. 5b), whereas the $\triangle a t l E$ strain had formed scattered small clumps with low amounts of extracellular DNA (Fig. 5d). The $\Delta a t l E(\mathrm{pRC} 21)$ strain formed microcolonies containing large amounts of extracellular DNA similar to wild-type microcolonies (Fig. 5e, f).

Two-day-old flow-chamber-grown 1457 wild-type biofilms had a mean thickness of $\sim 40 \mu \mathrm{m}$ and contained large amounts of extracellular DNA (Fig. 6a, b). Two-day-old flow-chamber-grown $\Delta a t l E$ biofilms contained scattered small microcolonies with a mean thickness of $<10 \mu \mathrm{m}$, and only low amounts of extracellular DNA (Fig. 6c, d). The $\triangle a t l E(\mathrm{pRC} 21)$ strain formed biofilms with extracellular DNA similar to that of wild-type biofilms (Fig. 6e, f).

\section{Occurrence of dead cells in S. epidermidis biofilms}

In addition to extracellular DNA, DDAO staining will also stain dead cells. It is therefore likely that part of the observed DDAO staining is due to the presence of dead cells in the biofilms. In order to investigate whether dead cells were present in the S. epidermidis biofilms we employed PI staining. Although PI can be used to map the location of extracellular DNA in biofilms if the sensitivity of the CLSM microscope is set to a very high level (Allesen-Holm et al., 2006), PI will visualize dead cells (which are permeable and have a very high DNA concentration) when normal settings of the microscope are 

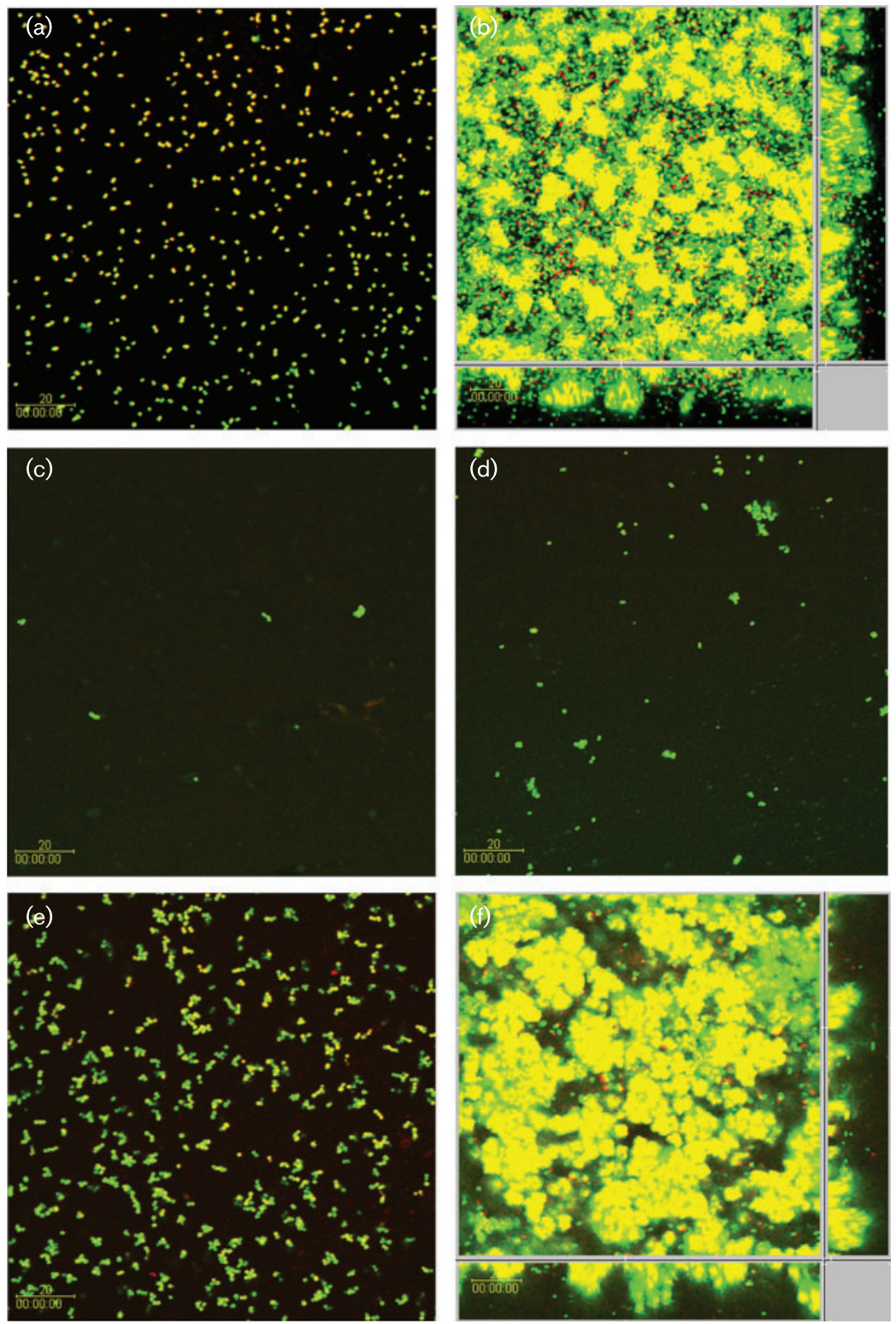

Fig. 5. Biofilms of $S$. epidermidis 1457 wildtype $(\mathrm{a}, \mathrm{b}), \Delta$ at/E $(\mathrm{c}, \mathrm{d})$ and $\Delta$ at/E(pRC21) (e, f) were grown in static chambers with TSB medium for $1 \mathrm{~h}(\mathrm{a}, \mathrm{c}, \mathrm{e})$ or $24 \mathrm{~h}(\mathrm{~b}, \mathrm{~d}, \mathrm{f})$, and then stained with SYTO 9 (green) and DDAO (red), upon which microscopic investigation was performed by the use of CLSM. The green and red signals are shown in the same micrographs, whereby cells surrounded by extracellular DNA appear yellow. Bars, $20 \mu \mathrm{m}$. used (Haagensen et al., 2007). With appropriate settings of the CLSM microscope, the Live_Dead reagents (SYTO 9 and PI) will therefore stain live cells green and dead cells red.

Live_Dead staining indicated that virtually all of the attached cells $[1457$ wild-type, $\Delta a t l E$ strain and $\Delta a t l E(\mathrm{pRC} 21)$ strain] in newly inoculated flow chambers were alive (data not shown). Live_Dead staining in twoday-old flow-chamber-grown S. epidermidis biofilms suggested that the microcolonies formed by the wild-type contained dead cells in the centre (Fig. 7a), whereas the small cell aggregates formed by the $\Delta a t l E$ strain contained almost no dead cells (Fig. 7b); the microcolonies formed by the $\Delta a t l E(\mathrm{pRC} 21)$ strain contained dead cells in the centre similar to the wild-type microcolonies (Fig. 7c).

\section{Autolysis of S. epidermidis 1457 wild-type and $\Delta$ atIE mutant cells}

Because our experiments indicated that the presence of extracellular DNA in S. epidermidis cultures and biofilms is mainly due to AtlE-mediated cell lysis, we compared autolysis of the S. epidermidis 1457 wild-type and $\Delta a t l E$ strains. As demonstrated in Fig. 8, the $\Delta a t l E$ cells exhibited a much lower rate of autolysis than those of the parental strain, confirming that AtlE has autolytic activity in our S. epidermidis strain.

\section{DISCUSSION}

In the present study we provide evidence that extracellular DNA is a major component contributing to initial 

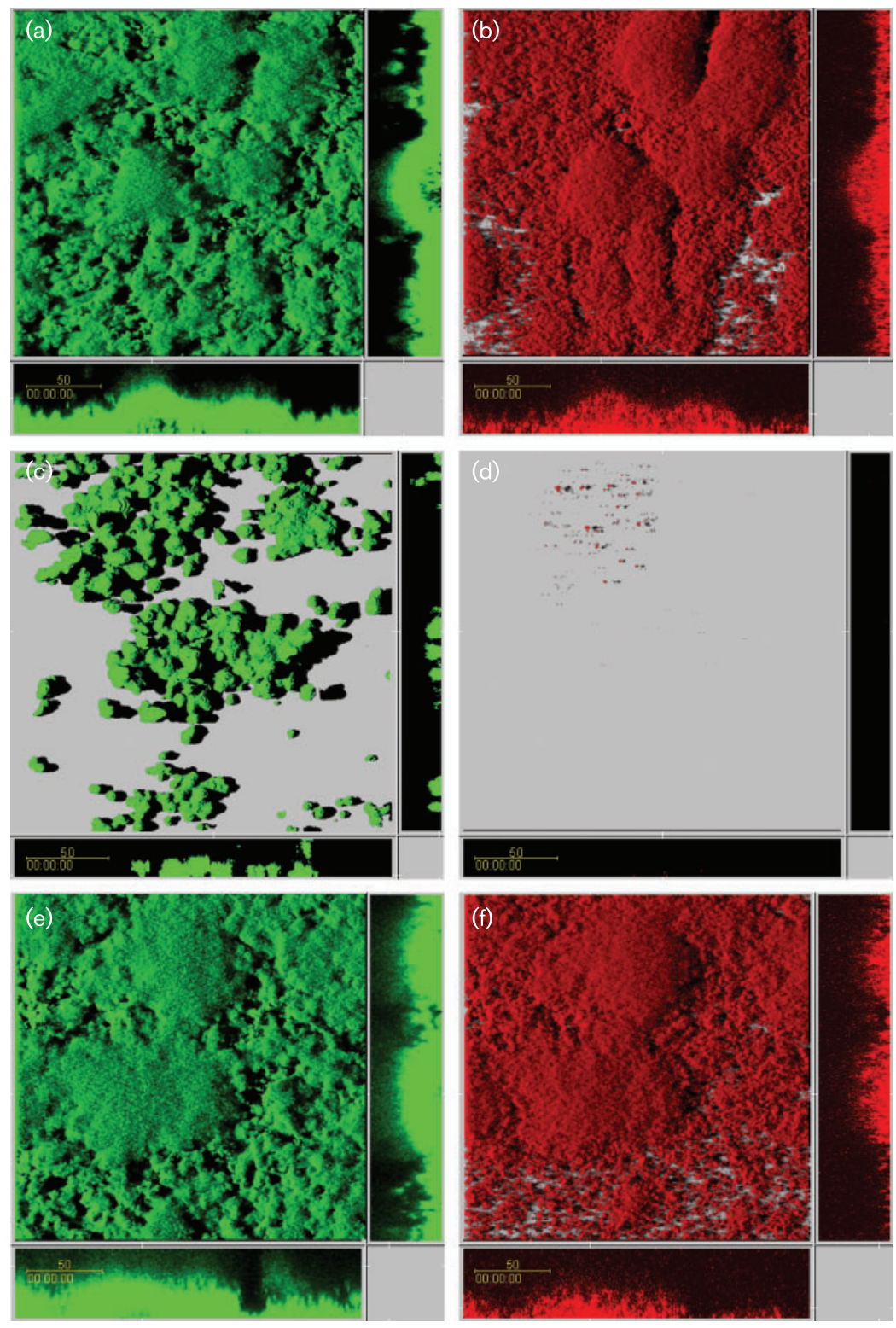

Fig. 6. Biofilms of $S$. epidermidis 1457 wildtype (a, b), $\Delta$ at IE (c, d) and $\Delta a t / E(p R C 21)(e, f)$ were grown for 2 days in flow chambers irrigated with minimal medium, and were then stained with SYTO 9 and DDAO, upon which microscopic investigation was performed by CLSM. Cells (green) and extracellular DNA (red) are shown in separate micrographs acquired at the same locations. The central pictures show top-down views, and the flanking pictures show side views. Bars, $50 \mu \mathrm{m}$. attachment of $S$. epidermidis to both plastic and glass surfaces. DNase I treatment prevented attachment and biofilm formation of S. epidermidis, whereas RNase treatment and the presence of heat-inactivated DNase I had no effect. Extracellular DNA was found to be abundant in $S$. epidermidis biofilms under both static and hydrodynamic conditions. Because extracellular DNA can function as a cell-to-cell connector (Whitchurch et al. 2002; Nemoto et al., 2003; Petersen et al., 2004, 2005), it is likely that extracellular DNA also has a role in the accumulative phase of S. epidermidis biofilm formation. In support of this hypothesis, about half of the biofilm biomass was dispersed when DNase I was added to six-hour-old S. epidermidis biofilms (except for one out of the six strains tested). However, DNase I treatment could not disperse more mature biofilms of $S$. epidermidis, indicating that extracellular DNA may be most critical as a matrix component in the initial phase of S. epidermidis biofilm formation. The possibility that proteases or macromolecules which may interfere with DNase I activity are present in mature $S$. epidermidis biofilms has not been investigated. Preliminary experiments indicated that addition of exogenous DNA to microtitre-plate cultures did not stimulate biofilm formation (data not shown), indicating that the DNA has to be released directly from the cells in order to stimulate biofilm formation. However, further investigations are needed before firm conclusions can be drawn on this issue.

Comparative PCR analysis suggested that the extracellular DNA present in S. epidermidis cultures is similar to genomic DNA, which is in accordance with the hypothesis that it originates from lysis of a small subpopulation of the S. epidermidis bacteria. DNA release from S. epidermidis appears to be mainly mediated by the autolysin protein 

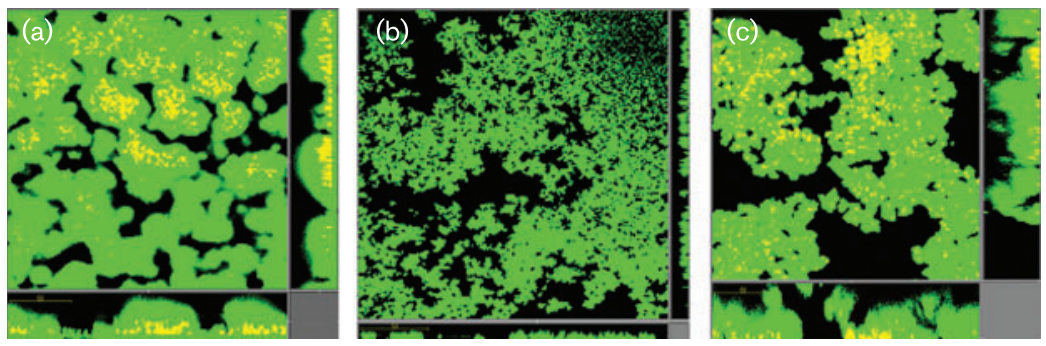

Fig. 7. Biofilms of $S$. epidermidis 1457 wildtype (a), $\Delta a t / E$ (b) and $\Delta a t / E(p R C 21)$ (c) were grown for 2 days in flow chambers irrigated with minimal medium, and were then stained with SYTO 9 and PI, upon which microscopic investigation was performed by CLSM. The central pictures show horizontal optical sections, and the flanking pictures show side views. Live cells appear green and dead cells appear yellow. Bars, $50 \mu \mathrm{m}$.

AtlE, since inactivation of atlE reduced DNA release by more than $90 \%$. Because Atle has autolytic activity, it is likely that AtlE activity results in lysis of a small fraction of the bacteria, resulting in the production of extracellular DNA which promotes surface attachment of the remaining population. AtlE-mediated cell lysis may also occur in established biofilms, as extracellular DNA was found in biofilms of the S. epidermidis wild-type but not in microcolonies of the atlE mutant. Similar mechanisms for extracellular DNA production have been reported for Streptococcus pneumoniae, Acinetobacter calcoacaticus and $P$. aeruginosa (Steinmoen et al., 2002; Palmen \& Hellingwerf, 1995; Allesen-Holm et al., 2006).

The dead cells observed in the centre of wild-type microcolonies in flow-chamber-grown S. epidermidis biofilms may be connected to AtlE-mediated cell lysis if the kinetics of the process are such that the intermediary dead cells are present for some time before they lyse. This would be in accordance with the fact that virtually no dead cells were observed in biofilms formed by the atlE mutant. However, the fact that no dead cells were detected in the initial phase of biofilm development of the wild-type indicates that AtlE-mediated lysis is a fast process, where intermediary dead cells are present only for a very short time. It is possible therefore that AtlE-mediated DNA release occurs in S. epidermidis biofilms without the presence of detectable amounts of dead cells. Although the dead cells in the

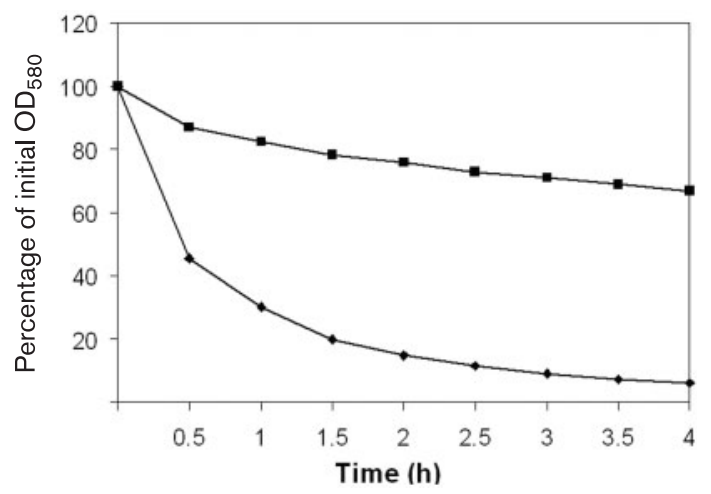

Fig. 8. Autolysis of $S$. epidermidis 1457 wild-type $(\boldsymbol{)})$ and $\Delta$ at/E (घ) strains in medium with Triton X-100. centre of the microcolonies in S. epidermidis wild-type biofilms are anticipated to eventually lyse and contribute to the pool of extracellular DNA in the biofilm, the process may not be connected to AtlE activity. The finding that the wild-type biofilms contained more dead cells than the AtlE biofilms could be related to the differences in microcolony size, which may in turn result in different nutritional conditions and different concentrations of waste products.

There may be factors other than AtlE involved in DNA release from S. epidermidis. Recently, another autolysin protein was identified in S. epidermidis, Aae, which has bacteriolytic activity and adhesive properties, although its role in DNA release remains to be investigated (Heilmann et al., 2003). More recently, Resch et al. (2005) have reported the presence of phage activities in both planktonic and biofilm cells of Staphylococcus aureus, and phages were present over a much longer period in biofilm cultures than in planktonic supernatants. It is reasonable to believe that phage release resulting in cell lysis may occur during biofilm formation of S. epidermidis as well. We have found a locus in the genome of S. epidermidis which is homologous to the comE locus (comEA, comEB and comEC) reported to be associated with genetic transformation and DNA release in Bacillus subtilis (Inamine \& Dubnau, 1995). However, further investigation is needed to elucidate the role of this locus in S. epidermidis.

Biofilm formation and extracellular DNA release have been reported to be regulated by quorum sensing in $P$. aeruginosa (Davies et al., 1998; Allesen-Holm et al., 2006). In S. epidermidis it has been reported that the expression of AtlE and biofilm formation are increased in an agr quorumsensing mutant (Vuong et al., 2003), implying that AtlEmediated DNA release may be regulated by the agr quorum-sensing system. Although quorum sensing may be a common denominator in the regulation of DNA release in biofilms of $P$. aeruginosa and S. epidermidis, the available evidence suggests that it has opposite effects in the two organisms.

Extracellular DNA has now been shown to play a role in biofilm formation for representatives of the genera Pseudomonas (Whitchurch et al., 2002; Nemoto et al., 2003), Streptococcus (Petersen et al., 2004, 2005) and Staphylococcus (this study). Because virtually all bacterial populations generate extracellular DNA (e.g. Lorenz et al., 1991), and because most bacterial species bind to DNA (e.g. 
Dubnau, 1999), extracellular DNA may be a common matrix component in bacterial biofilms.

\section{ACKNOWLEDGEMENTS}

We thank Professor Friedrich Götz, University of Tübingen, for providing plasmids pRC21 and pRB473, and Janus Haagensen for help with confocal microscopy. This work was supported by the State Key Program of Basic Research of China (973) (2002CB512803), the Hi-Tech Program of China (863) (2004AA223080), the Scientific Technology Development Foundation of Shanghai (055407069), the China International Science and Technology Cooperation Projects funded by the Ministry of Science and Technology of China (2003DFB00023, 2006DFA32760), and the Danish Research Councils. Z. Q. was supported by the Danida fellowship during his visit at BioCentrum-DTU.

\section{REFERENCES}

Allesen-Holm, M., Barken, K. B., Yang, L., Klausen, M., Webb, J. S., Kjelleberg, S., Molin, S., Givskov, M. \& Tolker-Nielsen, T. (2006). A characterization of DNA release in Pseudomonas aeruginosa cultures and biofilms. Mol Microbiol 59, 1114-1128.

Bruckner, R. (1997). Gene replacement in Staphylococcus carnosus and Staphylococcus xylosus. FEMS Microbiol Lett 151, 1-8.

Brunskill, E. W. \& Bayles, K. W. (1996). Identification and molecular characterization of a putative regulatory locus that affects autolysis in Staphylococcus aureus. J Bacteriol 178, 611-618.

Christensen, G. D., Simpson, W. A., Bisno, A. L. \& Beachey, E. H. (1982). Adherence of slime-producing strains of Staphylococcus epidermidis to smooth surfaces. Infect Immun 37, 318-326.

Christensen, G. D., Simpson, W. A., Younger, J. J., Baddour, L. M., Barrett, F. F., Melton, D. M. \& Beachey, E. H. (1985). Adherence of coagulase-negative staphylococci to plastic tissue culture plates: a quantitative model for the adherence of staphylococci to medical devices. J Clin Microbiol 22, 996-1006.

Clark, J. D. \& Maaløe, O. (1967). DNA replication and the cell cycle in Escherichia coli cells. J Mol Biol 23, 99-112.

Costerton, J. W., Lewandowski, Z., Caldwell, D. E., Korber, D. R. \& Lappin-Scott, H. M. (1995). Microbial biofilms. Annu Rev Microbiol 49, 711-745.

Davies, D. G., Parsek, M. R., Pearson, J. P., Iglewski, B. H., Costerton, J. W. \& Greenberg, E. P. (1998). The involvement of cell-to-cell signals in the development of a bacterial biofilm. Science 280, 295-298.

Dubnau, D. (1999). DNA uptake in bacteria. Annu Rev Microbiol 53, 217-244.

Flemming, H. C., Wingender, J., Griegbe, T. \& Mayer, C. (2000). Physicochemical properties of biofilms In Biofilms: Recent Advances in their Study and Control, pp. 19-34. Edited by L. V. Evans. Amsterdam: Harwood Academic Publishers.

Gill, S. R., Fouts, D. E., Archer, G. L., Mongodin, E. F., Deboy, R. T., Ravel, J., Paulsen, I. T., Kolonay, J. F., Brinkac, L. \& other authors (2005). Insights on evolution of virulence and resistance from the complete genome analysis of an early methicillin-resistant Staphylococcus aureus strain and a biofilm-producing methicillinresistant Staphylococcus epidermidis strain. J Bacteriol 187, 24262438.

Gotz, F. (2002). Staphylococcus and biofilms. Mol Microbiol 43, $1367-1378$.
Gotz, F., Heilmann, C. \& Cramton, S. E. (2000). Molecular basis of catheter associated infections by staphylococci. Adv Exp Med Biol 485, 103-111.

Haagensen, J. A., Klausen, M., Ernst, R. K., Miller, S. I., Folkesson, A., Tolker-Nielsen, T. \& Molin, S. (2007). Differentiation and distribution of colistin- and sodium dodecyl sulfate-tolerant cells in Pseudomonas aeruginosa biofilms. J Bacteriol 189, 28-37.

Heilmann, C., Gerke, C., Perdreau-Remington, F. \& Gotz, F. (1996a). Characterization of Tn917 insertion mutants of Staphylococcus epidermidis affected in biofilm formation. Infect Immun 64, 277-282.

Heilmann, C., Schweitzer, O., Gerke, C., Vanittanakom, N., Mack, D. \& Gotz, F. (1996b). Molecular basis of intercellular adhesion in the biofilm-forming Staphylococcus epidermidis. Mol Microbiol 20, 1083-1091.

Heilmann, C., Hussain, M., Peters, G. \& Gotz, F. (1997). Evidence for autolysin-mediated primary attachment of Staphylococcus epidermidis to a polystyrene surface. Mol Microbiol 24, 1013-1024.

Heilmann, C., Thumm, G., Chhatwal, G. S., Hartleib, J., Uekotter, A. \& Peters, G. (2003). Identification and characterization of a novel autolysin (Aae) with adhesive properties from Staphylococcus epidermidis. Microbiology 149, 2769-2778.

Inamine, G. S. \& Dubnau, D. (1995). ComEA, a Bacillus subtilis integral membrane protein required for genetic transformation, is needed for both DNA binding and transport. J Bacteriol 177, 3045-3051.

Jager, S., Mack, D., Rohde, H., Horstkotte, M. A. \& Knobloch, J. K. (2005). Disintegration of Staphylococcus epidermidis biofilms under glucose-limiting conditions depends on the activity of the alternative sigma factor $\sigma^{\mathrm{B}}$. Appl Environ Microbiol 71, 5577-5581.

Lorenz, M. G., Gerjets, D. \& Wackernagel, W. (1991). Release of transforming plasmid and chromosomal DNA from two cultured soil bacteria. Arch Microbiol 156, 319-326.

Mack, D. (1999). Molecular mechanisms of Staphylococcus epidermidis biofilm formation. J Hosp Infect 43 (Suppl.), S113-S125.

Mack, D., Siemssen, N. \& Laufs, R. (1992). Parallel induction by glucose of adherence and a polysaccharide antigen specific for plasticadherent Staphylococcus epidermidis: evidence for functional relation to intercellular adhesion. Infect Immun 60, 2048-2057.

Mah, T. F. \& O'Toole, G. A. (2001). Mechanisms of biofilm resistance to antimicrobial agents. Trends Microbiol 9, 34-39.

Moller, S., Sternberg, C., Andersen, J. B., Christensen, B. B., Ramos, J. L., Givskov, M. \& Molin, S. (1998). In situ gene expression in mixedculture biofilms: evidence of metabolic interactions between community members. Appl Environ Microbiol 64, 721-732.

Nemoto, K., Hirota, K., Murakami, K., Taniguti, K., Murata, H., Viducic, D. \& Miyake, Y. (2003). Effect of Varidase (streptodornase) on biofilm formed by Pseudomonas aeruginosa. Chemotherapy 49, 121-125.

Palmen, R. \& Hellingwerf, K. J. (1995). Acinetobacter calcoaceticus liberates chromosomal DNA during induction of competence by cell lysis. Curr Microbiol 30, 7-10.

Petersen, F. C., Pecharki, D. \& Scheie, A. A. (2004). Biofilm mode of growth of Streptococcus intermedius favored by a competencestimulating signaling peptide. J Bacteriol 186, 6327-6331.

Petersen, F. C., Tao, L. \& Scheie, A. A. (2005). DNA binding-uptake system: a link between cell-to-cell communication and biofilm formation. J Bacteriol 187, 4392-4400.

Qin, Z., Yang, X., Yang, L., Jiang, J., Ou, Y., Molin, S. \& Qu, D. (2007). Formation and properties of in vitro biofilms of ica-negative Staphylococcus epidermidis clinical isolates. J Med Microbiol 56, 83-93. 
Resch, A., Fehrenbacher, B., Eisele, K., Schaller, M. \& Gotz, F. (2005). Phage release from biofilm and planktonic Staphylococcus aureus cells. FEMS Microbiol Lett 252, 89-96.

Rupp, M. E. \& Archer, G. L. (1994). Coagulase-negative staphylococci: pathogens associated with medical progress. Clin Infect Dis 19, 231-243.

Rupp, M. E., Fey, P. D., Heilmann, C. \& Gotz, F. (2001). Characterization of the importance of Staphylococcus epidermidis autolysin and polysaccharide intercellular adhesin in the pathogenesis of intravascular catheter-associated infection in a rat model. J Infect Dis $\mathbf{1 8 3}$, 1038-1042.

Steinmoen, H., Knutsen, E. \& Havarstein, L. S. (2002). Induction of natural competence in Streptococcus pneumoniae triggers lysis and DNA release from a subfraction of the cell population. Proc Natl Acad Sci U S A 99, 7681-7686.
Stewart, P. S. \& Costerton, J. W. (2001). Antibiotic resistance of bacteria in biofilms. Lancet 358, 135-138.

Sutherland, I. W. (2001). The biofilm matrix - an immobilized but dynamic microbial environment. Trends Microbiol 9, 222-227.

Vuong, C., Gotz, F. \& Otto, M. (2000). Construction and characterization of an agr deletion mutant of Staphylococcus epidermidis. Infect Immun 68, 1048-1053.

Vuong, C., Gerke, C., Somerville, G. A., Fischer, E. R. \& Otto, M. (2003). Quorum-sensing control of biofilm factors in Staphylococcus epidermidis. J Infect Dis 188, 706-718.

Whitchurch, C. B., Tolker-Nielsen, T., Ragas, P. C. \& Mattick, J. S. (2002). Extracellular DNA required for bacterial biofilm formation. Science 295, 1487.

Edited by: P. E. Kolenbrander 